\title{
DIGNIDADE HUMANA E O SUPREMO TRIBUNAL FEDERAL
}

\author{
HUMAN DIGNITY AND THE FEDERAL SUPREME COURT
}

\author{
Pedro Coelho Marques ${ }^{1}$ \\ Guilherme Camargo Massaú ${ }^{\text {II }}$ (10
}

\footnotetext{
${ }^{\mathrm{I}}$ Universidade Federal de Pelotas, Pelotas, RS, Brasil. Mestrando em Direito. E-mail: marquespdr@yahoo.com

${ }^{\text {II } U n i v e r s i d a d e ~ F e d e r a l ~ d e ~ P e l o t a s, ~}$ Pelotas, RS, Brasil. Doutor em Direito. E-mail: uassam@gmail.com
}

Resumo: Estuda-se a dignidade humana enquanto princípio fundamental para o Estado brasileiro, qualificado como tal na Constituição da República, e suas aproximaçóes designadas em julgados do Supremo Tribunal Federal. Trazse, para maior aprofundamento, as conceituaçôes feitas pela doutrina que, a despeito de dar à dignidade humana atributos de vagueza em seus contornos, tende a considerá-la como um valor intrínseco ao ser humano. A partir da análise da dignidade humana no decorrer da história, comparou-se o enfrentamento do princípio feito por doutrinadores antigos e contemporâneos com o que o STF expóe nos julgamentos de casos notórios. Com tal comparaçáo, demonstrou-se que, em que pese o fato de a dignidade humana não ter um conteúdo cristalino e universal, o que por vezes faz com que seu uso seja banalizado, ainda assim consolida-se como um fundamento do Estado brasileiro não somente no texto constitucional, senão também no entendimento da Suprema Corte. Utilizou-se o método indutivo, a pesquisa é do tipo bibliográfica e tem caráter qualitativo.

Palavras-chave: Dignidade Humana; Fundamento; STF.

Abstract: The object of study is the human dignity as a fundamental principle for the Brazilian State, as in the Constitution of that country, and its designated attributes by the Supreme Court decisions. In order of giving a deeper conceptualization to the understanding of the doctrine is brought. In spite of its blurry contours, tends to consider an intrinsic value of the human being. From the analysis of human dignity throughout history, the confrontation of the principle made by ancient and contemporary indoctrinators was compared with what the STF exposes in the judgments of notorious cases. With this comparison, it was shown that, despite the fact that human dignity does not have a crystalline and universal content, which sometimes causes its use to be trivialized, it still consolidates itself as a foundation of the Brazilian State not only in the constitutional text, but also in the understanding of the Supreme Court.

Keywords: Human Dignity; Foundation; Supreme Court. 


\section{Introdução}

O presente texto tem como escopo o estudo da dignidade humana conforme exposta e exteriorizada pelo Supremo Tribunal Federal (STF) em seus julgados. Entendese que a dimensão prática do Direito atribui significado decisivo para a compreensão dos limites e do conteúdo da dignidade humana. Embora, não se pode descurar da análise teórica do seu significado, já que a base teórica disseca, analiticamente, o que deve ou não ser considerado dignidade. Por isto, inicialmente, tratar-se-á das nuances materiais do conceito do princípio.

Introdutoriamente, explorar-se-á acerca da conceituação e da abordagem doutrinária a respeito do princípio. Conforme se depreende do estudo realizado, a dignidade da pessoa humana tem contornos um tanto vagos, fato que pode enfraquecer o conceito ao dar margem à tentativa de sua utilização em situaçóes nas quais ele náo tem aplicação alguma. Com isso, parte minoritária da doutrina tende a classificá-lo, inclusive, como um "conceito inútil”, ou uma "repetição vaga” de noções já existentes, como a autonomia e o respeito pelo outro.

$\mathrm{Na}$ contramão desta ideia adotada por pequena parte da doutrina, o conceito da dignidade da pessoa humana é tido como um valor intrínseco ao ser humano que dá a ele a garantia de existir como um ser especial e único, tendo protegidos seus direitos fundamentais em um exercício de democracia e cidadania.

Como direito fundamental, a dignidade da pessoa humana tem aplicação imediata e, pode-se afirmar, encontra-se pautada no direito à vida, manifestando-se fortemente impregnada de uma visão política. Atrelada a ideia de um espectro político, a dignidade humana é tida para o STF como um valor-fonte constitucional e, conforme dito especificamente pela Min. Carmen Lúcia1: o princípio mais importante da Constituição Federal (CRFB) de 1988.

Portanto, expóe-se aqui o entendimento do STF a fim de situar o significado de dignidade humana na prática do Poder Judiciário brasileiro. Aparentemente, existe alinhamento entre a doutrina majoritária e o STF, no sentido de corroborar a óbvia posição do princípio como fundamento constitucional e, além disso, assentar-se como critério interpretativo "in dúbio pro dignitate".

O STF, nos julgados colacionados, tratou com destaque da dignidade da pessoa humana, o que denota-se do fato de que, em que pese os contornos imprecisos do princípio, ter sido adotado para decidir sobre o reconhecimento da uniáo estável entre pessoas do mesmo sexo como uma entidade familiar, o incentivo à políticas públicas de inclusão de portadores de necessidades especiais à sociedade, da vedação ao uso de

1 SUPREMO TRIBUNAL FEDERAL. http://www.stf.jus.br/portal/cms/verNoticiaDetalhe. asp?idConteudo=386320 acesso em 07/01/2020. 
algemas em casos de desnecessidade, dentre alguns outros também trabalhados no presente estudo. Por fim, salienta-se que foram analisadas decisóes do STF proferidas tanto em plenário quanto em órgãos fracionários para que se obtivesse uma comparação em busca do melhor entendimento possível do impreciso conteúdo conceitual da dignidade da pessoa humana.

\section{0 princípio da dignidade da pessoa humana}

Ainda que haja - não só na doutrina senão também na jurisprudência - posição de que a dignidade da pessoa humana precede a CRFB de 1988, é este documento que, no caput do seu art. $5^{\circ}$, orientado pelo princípio da dignidade humana e pelos conexos princípios da isonomia e universalidade, reconhece como titular de direitos fundamentais toda e qualquer pessoa, seja ela brasileira ou estrangeira no país ${ }^{2}$.

Percebe-se, portanto, que a dignidade da pessoa humana, juntamente com a soberania, cidadania, valores sociais do trabalho e da livre iniciativa e o pluralismo político, consolidou-se como um fundamento do Estado brasileiro, conforme exposto no Art. $1^{\circ}$, III, da CRFB. Destarte, por ser princípio fundamental, a dignidade humana, até mesmo pela sua característica, emana eficácia irradiante impondo diretrizes para a aplicação de todas as demais normas do ordenamento jurídico brasileiro, constitucional ou infraconstitucional. Por conseguinte, tal princípio é critério normativo da interpretação das normas jurídicas.

Por princípio, devemos considerar que, conforme entendimento de Ingo Wolfgang $S_{\text {Sarlet }}^{3}$, não se consegue conceituar precisamente a dignidade da pessoa humana. $\mathrm{Na}$ mesma toada, deve-se perceber que justamente por esta imprecisão, a definição do âmbito de proteçáo na esfera do Direito continua a ser um desafio a todos que se ocupam do tema. Tanto que a incidência do suporte fático do Art. $1^{\circ}$, III, da CRFB não se dá de forma isolada. Ela se dará conjugada com outro suporte fático, a depender do caso concreto. Por isto, entende-se que este conceito constitui-se em bússola para a eticidade, mesmo que sejam inumeráveis os significados e diversas as noções dele concebidas ${ }^{4}$.

A fim de obter uma compreensão o mais exata quanto possível da dignidade humana, recorremos a dimensóes históricas do conceito conforme explorado por Sarlet ${ }^{5}$, no sentido de que deve-se rastrear a evolução da palavra em direção ao conteúdo

2 SARLET, Ingo Wolfgang. A eficácia dos direitos fundamentais: uma teoria dos direitos fundamentais na perspectiva constitucional. 13. ed. Porto Alegre: Livraria do Advogado, 2018, p. 217.

3 SARLET, Ingo Wolfgang. Dignidade da pessoa humana na jurisprudência do Supremo Tribunal Federal. Revista Jurídica da Universidade do Sul de Santa Catarina, Santa Catarina, 2017, p. 20-21;

4 LIBRELOTTO, Gicélia. Dignidade da Pessoa Humana: reflexóes jurídicas e filosóficas sobre o conceito. 2017. $107 \mathrm{f}$. Dissertação (Mestrado). Pontifícia Universidade Católica do Rio Grande do Sul, Programa de Pós-Graduação em Filosofia, Porto Alegre, 2017, p. 12.

5 SARLET, Ingo Wolfgang. Dimensóes da dignidade: ensaios de filosofia do direito e direito constitucional. 2. ed. Porto Alegre: Livraria do Advogado, 2009; 
conceitual, para que seja plausível um entendimento do núcleo. $\mathrm{O}$ autor vê em Hegel e em sua definição de pessoa, por exemplo, a formação de um contexto em que seja feita uma construção e reconstrução da caracterização do homem. Assim, percebe-se que:

A pessoa concreta [...] é, na condição de uma totalidade de carências, uma mistura de capricho e necessidade física, um princípio de sociedade civil. Mas a pessoa particular está, em essência, táo relacionada com outras pessoas particulares que cada qual se estabelece e encontra satisfaçáo por meio de outros e, ao mesmo tempo, pura e simplesmente por meio da forma da universalidade, que é aqui o Segundo princípio ${ }^{6}$.

Da Idade Média ao surgimento do Estado liberal, a dignidade constituiu-se como "um conceito associado ao status pessoal de alguns indivíduos ou à proeminência de determinadas instituiçôes" das pessoas eram levadas em conta para a atribuição da dignidade. Assim foi até o final do século XVIII, momento em que a dignidade passou a se relacionar com o ser humano - por si só - e com os direitos humanos.

O fato é que a dignidade, quando pensada em seu sentido pré-moderno, pressupóe uma sociedade hierarquizada, equivalendo à nobreza, eis que implicava em um tratamento especial, direitos exclusivos e privilégios. O desenvolvimento do conceito ocorreu apoiado no "pressuposto de que cada ser humano tem um valor intrínseco e desfruta de uma posição especial no universo"

Frise-se que, ainda que a ideia moderna da dignidade possa parecer antagônica à pré-moderna, não se pode assim pensar. Isto porque a noção atual não substitui a antiga, já que é produto de uma história diferente e que, na verdade, correu paralelamente à narrativa antiga ${ }^{9}$.

Percebe-se que a dignidade humana, na Idade Média, esteve entrelaçada com ideais religiosos. No que diz com a civilização ocidental, as tradiçôes éticas e religiosas se sobrepóem. Em Pico della Mirandola ${ }^{10}$ e seu discurso "Oração sobre a Dignidade do Homem" houve a justificação da importância da busca por conhecimento e a elevaçáo do homem e da razão ao centro do mundo ${ }^{11}$.

A noção da dignidade da pessoa humana, portanto, é um valor intrínseco ao ser humano, e foi construída desde a idade média, manifestando-se de formas mais variadas "não apenas no pensamento filosófico, como também em todos os ramos da arte" ${ }^{12}$.

6 MORRIS, Clarence. Os grandes flósofos do Direito. São Paulo: Martins Fontes, 2002, p. 316.

7 BARROSO, Luís Roberto. A dignidade da pessoa humana no direito constitucional contemporâneo: a construção de um conceito jurídico à luz da jurisprudência mundial. Trad. Humberto Laport de Mello. Belo Horizonte: Fórum, 2014, p. 13.

8 ibid. p. 14.

9 ibid. p. 14.

10 Vide: MASSAÚ, Guilherme. A dignidade humana em Pico della Mirandola. In: Revista Direitos Culturais. v. 7 , n. 13. Santo Ângelo, 2012.

11 ibid. p. 17.

12 LIBRELOTTO, Gicélia. Dignidade da Pessoa Humana: reflexöes jurídicas e filosóficas sobre o conceito. 2017. $107 f$. Dissertação (Mestrado). Pontifícia Universidade Católica do Rio Grande do Sul, Programa de Pós-Graduação 
A exemplo do que relata Immanuel Kant ${ }^{13}$, todas as coisas do universo possuem um preço ou uma dignidade. Quando se estiver diante do primeiro caso, tem-se que tal coisa pode ser substituída por outra que ao preço equivalha. De outra banda, quando o caso for de algo que se demonstre insubstituível por qualquer que seja o preço da coisa substituta, aí então estaremos diante de algo que compreende uma dignidade.

Como direito fundamental, a dignidade da pessoa humana tem aplicação imediata e encontra-se pautada no direito à vida e para além dela (e.g., proteção da imagem de pessoa falecida), manifestando-se fortemente impregnada de uma visão política. Neste sentido, aponta Sarlet ${ }^{14}$ :

Por isso, o preceito da dignidade da pessoa humana causa especiais dificuldades que resultam não apenas dos enraizamentos religiosos, filosóficos e históricos da dignidade da pessoa humana como também da dependência da respectiva situação global civilizacional e cultural da sociedade.

Não há, precisamente, um consenso quanto a uma definição genérica e abstrata da noção jurídica de dignidade. Em contrapartida, alguns contornos basilares do conceito foram definidos pela doutrina sem que houvesse uma imobilização, algo que iria de encontro "ao pluralismo e a diversidade de valores que se manifestam nas sociedades democráticas contemporâneas" ${ }^{15}$. Percebe-se isto quando a Corte Constitucional da Colômbia, em oposição a cortes constitucionais de outros países, e.g. Canadá e África do Sul, considerou a prostituição voluntária como uma profissão legítima ${ }^{16}$.

em Filosofia, Porto Alegre, 2017. p. 34.

13 KANT, Immanuel. Fundamentação da Metafísica dos Costumes e Outros Escritos, São Paulo: Martin Claret, 2002. p. 65.

14 SARLET, Ingo Wolfgang. Dimensóes da dignidade: ensaios de filosofia do direito e direito constitucional. 2. ed. Porto Alegre: Livraria do Advogado, 2009. p. 150.

15 id. Dignidade da pessoa humana na jurisprudência do Supremo Tribunal Federal. Revista Jurídica da Universidade do Sul de Santa Catarina, Santa Catarina, 2017, p. 22.

16 BARROSO, Luís Roberto. A dignidade da pessoa humana no direito constitucional contemporâneo: a construção de um conceito jurídico à luz da jurisprudência mundial. Trad. Humberto Laport de Mello. Belo Horizonte: Fórum, 2014, p. 29. 


\section{Destarte, o princípio da dignidade humana encontra-se positivado em $151^{17}$}

17 São as seguintes constituiçóes: Afghanistan (2004) Art. 6; Albania (1998) Preamble, Art. 3; Andorra (1993) Art. 4; Angola (2010) Preamble, Art. 1; Antigua and Barbuda (1981) Preamble; Armenia (1995) Art. 3, 1; Azerbaijan (1995) Art. 13, III, Art. 8, II, Art. 24, I, Art. 46, Art. 68, I; Bahrain (2002) Art. 18; Bangladesh (1972) 11; Barbados (1966) Preamble, a; Belarus (1994) Art. 25, Art. 42, Art. 53; Belgium (1831) Art. 23; Belize (1981) Preamble, a, 3 c; Benin (1990) Preamble; Bhutan (2008) Art. 9, 3; Bolivia (2009) Preamble, Art. 8, II, Art. 9, 2, Art. 21, 2, Art. 22, Art. 73, I; Bosnia and Herzegovinia (1995) Preamble; Bulgaria (1991) Preamble, Art. 4, 2, Art. 6, 1; Burkina Faso (1991) Preamble; Burundi (2005) Art. 13, Art. 14, Art. 21, Art. 52; Cambodia (1993) Art. 38, 2; Cape Verde (1980) Art. 1, 1, Art. 226; Central African Republic (2016) Preamble; Chad (1996) Preamble; Chile (1980) Art. 1; China (1982) Art. 38; Colombia (1991) Art. 1, Art. 21, Art. 51, Art. 53, 5, Art. 70, 2; Democratic Republic of the Congo (2005) Art. 11, Art. 18, 5; Côte D'Ivoire (2016) Preamble, Art. 2, 3, Art. 7, 3; Croatia (1991) Art. 25, Art. 35; Cuba (1976) Preamble, Art. 9, a, 3, Art. 16, Art, 42, Art. 43; Czech Republic (1993) Preamble; Dominica (1978) Preamble, a; Dominican Republic (2015) Preamble, Art. 5, Art. 7, Art. 8, Art. 38; Ecuador (2008) Preamble, Art. 11, 7, Art. 84, Art. 158, 3; Egypt (2004) Preamble, Art. 51, Art. 55, Art. 56, Art. 78; El Salvador (1983) Art. 10, Art. 11, 2; Equatorial Guinea (1991) Art. 5, a, Art. 13, 1, a, Art. 14; Eritrea (1997) Preamble, Art. 2, 2, Art. 16; Estonia (1992) Art. 10; Ethiopia (1994) Art. 21, 1, Art. 24, 1, Art. 29, 6, Art. 30, 2, Art. 91, 1; Fiji (2013) Preamble, Art. 1, e, Art. 3, 1, Art. 7, 1, a, Art. 13, 1, j; Finland (1999) Section 1, 2, Section 7, 2, Section 9, 4; Gambia (1996) Art. 28, 1, Art. 31, 1, Art. 37, 8; Georgia (1995) Art. 17; Germany (1949) Art. 1, Abs. 1; Ghana (1992) Art. 15, 1, Art. 33, 5, Art. 35, 4; Greece (1975) Art. 7 , 2, Art. 106, 2; Grenada (1973) Preamble, c; Guatemala (1985) Art. 4; Guinea (2010) Art. 5; Guinea-Bissau (1984) Art. 17, 1; Haiti (1987) Art. 44-1; Honduras (1982) Art. 59, 2, Art. 63, Art. 68, 3, Art. 76; Hungary (2011) Preamble, (Freedom and Responsibility) Art. II, Art. IX, 4, 5, Art. 37, 4; India (1949) Preamble, 39, F, 51A, e; Indonesia (1945) Art. 28G, Art. 28H, 3, Art. 32, 2; Iran (1979) Preamble-MassCommunicationMedia -, Art. 2, 6, Art. 22, Art. 121; Iraq (2005) Art. 37, First, A; Ireland (1937) Preamble; Israel (1958) Basic Law: Human Dignity and Liberty (1992) 1A, 2, Basic Law: The Government (2001) 39, d; Italy (1947) Art. 3, Art. 41, 2; Jamaica (1962) 13, 1, b, 14, 4; Japan (1946) Art. 24, 2; Jordan (1952) Art. 8, 2; Kazakhstan (1995) Art. 17; Kenya (2010) 10, 2, b, 19, 2, 20, 4, a, 24, 1, 28, 54, 1, a, 57, c, 244, d; Republic of Korea (1948) Art. 10, Art. 32, 3, Art. 36, 1; Kosovo (2008) Art. 23; Kuwait (1962) Preamble, Art. 29; Kyrgyzstan (2010) Art. 20, 4 (6), 5 (1), Art. 22, 2, Art. 29, 1, Art. 33, 5; Latvia (1922) Preamble, Art. 95; Lybia (2011) Art. 7; Liechtenstein (1921) Art. 27bis; Lithuania (1992) Art. 25, 3, Macedonia (1991) Art. 11; Madagascar (2010) Art. 17, Art. 29; Malawi (1994) 12, 1, d, 19, 42, 1, b, 2, g, iv; Maldives (2008) 57, 68; Mauritania (1991) Preamble; Mexico (1917) Art. 1, 5, Art. 3, II, c, Art. 25, 1; Moldova (1994) Art. 1, 3, Art. 9, 2, Art. 32, 2; Monaco (1962) Art. 20, 2; Mongolia (1992) Art. 16, 17, Art. 17, 2; Montenegro Art. 25, 3, Art. 27, 1, Art. 28, 1, Art. 31, 1, Art. 47, 2; Morocco (2011) Preamble, Art. 22, 2, Art. 161; Mozambique (2004) Art. 48, 6, Art. 119, 3, Art. 120, 1; Myanmar (2008) 44; Namibia (1990) Preamble, Art. 8, Art. 98, 1; Nepal (2015) 16, 1; New Zealand (1952) Bill of Rights Act (1990) 23, 5; Nicaragua (1987) Art. 5, Art. 6, Art. 33, 2, 2.1, Art. 82, 1; Niger (2010) Preamble, Art. 50, Art. 74, Art. 89, Art. 158, 1; Nigeria (1999) 17, 2, b, 21, a, 24, c, 34, 1; Oman (1996) Art. 31; Pakistan (1973) 11, 4, b, 14, 1; Panama (1972) Preamble, Art. 17, 2, Art. 122; Papua New Guinea (1975) Preamble, 36, 1, 37, 17, 39; Peru (1993) Art. 1, Art. 3, Art. 7, Art. 23, 3; Philippines (1987) Art. II, sec. 11, Art. XIII, sec. 1; Poland (1997) Preamble, Art. 30; Portugal (1976) Art. 1, Art. 59, 1, b, Art. 67, 2, e; Romania (1991) Art. 1, 3; Russian (1993) Art. 21, 1; Rwanda (2003) Art. 23, 1, Art. 38, 2; Saint Kitts and Nevis (1983) Preamble, a; Saint Lucia (1978) Preamble, e; Saint Vincent and Grenadines (1978) Preamble, c; Sao Tome and Principe (1975) Preamble; Saudi Arabia (1992) Art. 39; Serbia (2006) Art. 19, Art. 23, 1, Art. 28, 1, Art. 69; Seychelles (1993) Preamble, 16; Sierra Leone (1991) 8, 2, b, 13, e; Slovakia (1992) Art. 12, 1, Art. 19, 1; Slovenia (1991) Art. 21, Art. 34; Solomon Island (1978) Preamble; Somalia (2012) Art. 10; South Africa (1996) 1, a, 7, 1, 10, 35, 2, e, 36, 1, 39, 1, a; South Sudan (2011) Preamble, 1, 5, 11, 17, 1, g, 35, 2, 38, f, 169, 6; Spain (1978) Section 10, 1; Sri Lanka (1978) Preamble; Sudan (2005) 1, 2, 28, 45, 1; Suriname (1987) Art. 16, 3; Swaziland (2005) 18, 1, 30, 1, 57, 2, 60, 6; Sweden (1974) Art. 2; Switzerland (1999) Art. 7, Art. 118b, 1, Art. 119, 2, Art. 119e; Syrian Arab Republic (2012) Preamble, Art. 19, Art. 33, 1; Taiwan (1947) Art. 10, 6; Tajkistan (1994) Art. 5, e; Tanzania (1977) 9, a, f, 12, 2, 13, 6, d, 25, 1; Thailand (2017) Section 4, Section 26, Section 32; Timor-Leste (2002) Art. 1, 1; Togo (1992) Preamble, Art. 11, 1, Art. 28, 3; Trinidad and Tobago (1976) Preamble; Tunisia (2014) Art. 23, Art. 30, 1, Art. 47, 1; Turkey (1982) Art. 17, 3; Turkmenistan (2008) Art. 4, 2, Art. 31, Art. 60; Tuvalu (1986) Preamble (6), 12, c, 15, 27, 3, f, 29, c; Uganda (1995) XVI, XXIV, 24, 35, 1; Ukraine (1996) Art. 3, Art. 21, 1, Art. 28, 1; Uzbekistan (1992) Art. 13, Art, 27, 1, Art. 34, 2, Art. 48; Venezuela (1999) Art. 3, Art. 46, Art. 47, Art. 55, Art. 80, Art. 81, Art, 332; Viet Nam (1992) Art. 20, 1; Yemen (1991) Art. 48, a; Zambia (1991) Art. 8, d; Zimbabwe (2013) 3, 1, e, 16, 1, b, 50, 1, c, 5, d, 51, 56, 5 , 62, 4, 80, 1, 86, 2, 3, b, 141, iv, Section 87, 4, 1, c. 
constituições de 193 pesquisadas. Os exemplos excepcionais são as constituições dos Estados Unidos da América e da França ${ }^{18}$.

Sob argumentos como o de Neomi Rao ${ }^{19}$, de que o conceito seria marcadamente europeu, podendo enfraquecer o constitucionalismo americano - que se basearia em direitos individuais e não em valores comunitários -, por exemplo, autores buscam demonstrar a irrelevância e a não aplicação da dignidade humana na seara legal ${ }^{20}$. Há, ainda, quem diga que a dignidade se configura como um "conceito inútil", ou uma "repetição vaga" de noções já existentes, como a autonomia e o respeito pelo outro ${ }^{21}$.

Cabe frisar, ainda, a concepção da dignidade da pessoa humana a partir de uma perspectiva distinta. Trata-se da noção de dignidade para Letícia Martel ${ }^{22}$, que afirma que a dignidade, em verdade, deve ser observada como autonomia. Neste sentido, entende-se aqui a dignidade como fundamento e justificação dos direitos fundamentais e humanos, e por isso, existiriam quatro elementos importantes para a concepção de dignidade: (a) a capacidade de autodeterminação; (b) as condiçóes e as circunstâncias para florescimento da capacidade de autodeterminaçáo; (c) a universalidade; (d) a inerência da dignidade ao ser humano.

\section{A dignidade da pessoa humana para o Supremo Tribunal Federal}

Em que pese os contornos vagos e imprecisos, caracterizados por uma "ambiguidade e porosidade" ${ }^{23}$, o STF, como guardião da CRFB não pode furtar-se de decidir as lides que lhe cabem. Neste fato reside, em verdade, ponto que leva a discussão e, invariavelmente, a polêmica nos temas que atingem assuntos situados nos limites dos contornos vagos do conceito. Desta forma, intensifica-se a responsabilidade do STF em delimitar o conceito da dignidade da pessoa humana recai, já que o mesmo é o órgão do Poder Judiciário imbuído da jurisdição constitucional ${ }^{24}$. O STF tem invocado a dignidade humana em muitas situaçóes. Entre elas, o direito contra a autoincriminação, a proibição da tortura e do tratamento degradante e cruel, o direito de não ser algemado injustificadamente,

18 BARROSO, Luís Roberto. A dignidade da pessoa humana no direito constitucional contemporâneo: a construção de um conceito jurídico à luz da jurisprudência mundial. Trad. Humberto Laport de Mello. Belo Horizonte: Fórum, 2014, p. 55-56.

$19 \mathrm{RAO}$, Neomi. On the use and abuse of dignity in constitutional law. Columbia Journal of European Law, Spring, v. 2, n. 2, 2008.

20 ibid., p. 57.

21 ibid., p. 59.

22 MARTEL, Letícia de Campos Velho. Direitos fundamentais indisponiveis - os limites e os padröes do consentimento para a autolimitaçáo do direito fundamental à vida. 2010. 475f. Dissertaçáo (Doutorado). Universidade do Estado do Rio de Janeiro, Centro de Pós-Graduação em Direito Público, Rio de Janeiro, 2010, p. 155.

23 SARLET. Ingo Wolfgang. Dignidade da pessoa humana na jurisprudência do Supremo Tribunal Federal. Revista Jurídica da Universidade do Sul de Santa Catarina, Santa Catarina, 2017, p. 21.

24 ibid., p. 22-23. 
a falta de proteção constitucional para o discurso antissemita e o acolhimento de açóes afirmativas em benefício de pessoas com deficiências ${ }^{25}$.

Nos Estados Unidos da América, a título de exemplo, ainda que seja utilizado na jurisprudência desde a década de 1940, “o uso do conceito é episódico e pouco desenvolvido, relativamente incoerente e contraditório, além de carente de maior especificidade e clareza" ${ }^{26}$. Ainda que assim ocorra, nos últimos anos houve uma tendência de usar a dignidade humana, nas cortes americanas, como suporte para a resolução de casos envolvendo direitos fundamentais como o direito à privacidade, à igualdade, à proibição de penas cruéis e incomuns e do "direito de morrer".

Os precedentes sobre a dignidade humana nos tribunais constitucionais são os mais variados. Na África do Sul, e.g., a dignidade está expressamente incluída na Constituição e tem sido considerada tanto um valor fundacional quanto um direito exequível, tendo sido declarada a inconstitucionalidade da pena de morte no país ${ }^{27}$. Em Israel, o direito de um homem deixar a barba crescer, o direito de uma família realizar um funeral para seu parente falecido e o direito à paternidade foram assuntos discutidos e decididos com base no conceito em tela.

Também a jurisprudência internacional cita a dignidade humana em diversas ocasióes, como a título de exemplo, quando a Corte Interamericana de Direitos Humanos (CIDH) aborda "a violência psicológica, sexual e física contra detentos em prisão peruana, confinamento solitário e outras formas de encarceramento em condiçóes desumanas e desaparecimentos forçados" 28 . O mesmo órgão observa, ainda, um norte de responsabilização do Estado no que diz respeito à reparação do dano ocorrido.

$\mathrm{O}$ direito fundamental à vida foi mencionado pela $\mathrm{CIDH}$ no julgamento do caso das "Crianças de Rua" v. Guatemala, Inter-AmCHR Series C. No 77, ocorrido em 1999, no qual restou consignado que tal direito:

...inclui não apenas o direito de cada ser humano de não ser privado de sua vida arbitrariamente, mas também o direito de que ele não seja impedido de ter acesso às condiçôes que garantam uma existência digna ${ }^{29}$.

Mencione-se, ainda, a decisão da CIDH ocorrida no fim de 2010, na qual decidiu-se que crimes contra a humanidade perpetrados pela ditadura militar no Brasil (assassinato, tortura e desaparecimento forçado de pessoas), de 1964 até 1985, devem ser investigados, processados e punidos. $\mathrm{O}$ julgado foi prolatado contrariando frontalmente a Lei de Anistia promulgada pelo Congresso e, à época, mantida pelo STF.

25 ibid., p. 28.

26 BARROSO, Luís Roberto. A dignidade da pessoa humana no direito constitucional contemporâneo: a construção de um conceito jurídico à luz da jurisprudência mundial. Trad. Humberto Laport de Mello. Belo Horizonte: Fórum, 2014, p. 10.

27 ibid., p. 27.

28 ibid., p. 32.

29 ibid., p. 32. 
A dignidade da pessoa humana serve como princípio-base que norteia inúmeros outros direitos implícitos que dele surgem. $\mathrm{O}$ direito à liberdade de manifestaçáo de pensamento, a liberdade de orientação sexual, o direito a ter uma morte digna, dentre outros $^{30}$.

Para se falar sobre a dignidade humana para o STF, deve-se estabelecer a eficácia, o status e o conteúdo da dignidade humana na CRFB. Conforme Sarlet ${ }^{31}$ :

[...] a qualificação da dignidade da pessoa humana como princípio fundamental traduz a certeza de que o artigo $1^{\circ}$, inciso III, da CF, não contém apenas (embora também e acima de tudo) uma declarando de conteúdo ético e moral, mas que constitui norma jurídico-positiva dotada, em sua plenitude, de status constitucional formal e material e, como tal, inequivocamente dotado de eficácia e aplicabilidade, alcançando, portanto, a condição de valor jurídico fundamental da comunidade.

Por isso, considera-se que a CRFB confere uma unidade de sentido, de valor e de concordância prática ao sistema de direitos fundamentais. Para que ocorra tal unidade, a dignidade da pessoa humana tem papel essencial fazendo da pessoa fundamento e fim da sociedade e do Estado ${ }^{32}$.

A conexão entre a dignidade da pessoa humana e os direitos fundamentais é notória e pode ser explorada a partir da construção de um conceito material de direitos fundamentais. Ou seja, o princípio da dignidade humana é importante ao servir de ponto de partida para não apenas proteger, senão também criar direitos implícitos. Nos dizeres de Ingo Sarlet ${ }^{33}$ :

[...] o princípio da dignidade da pessoa humana assume posição de destaque, servindo como diretriz material tanto para a fundamentação de direitos implícitos (no sentido de posições jusfundamentais de cunho defensivo e/ou prestacional subentendidas nos direitos e garantias fundamentais da Constituição), quanto - e, de modo especial - para a identificação de direitos sediados em outras partes da Constituição.

Ainda que não se possa, conforme o exposto, designar à dignidade da pessoa humana um caráter de direito fundamental, de tal princípio se pode extrair "posiçóes jurídico-subjetivas fundamentais que tenham por objeto a proteçáo da dignidade contra novas ofensas e ameaças em princípio não alcançadas pelo âmbito de proteçáo dos direitos fundamentais." 34 .

Apontando para esta mesma direção, inúmeras são as decisôes do STF que relacionam a dignidade humana com direitos fundamentais. Tanto quanto aos direitos

30 LIBRELOTTO, Gicélia. Dignidade da Pessoa Humana: reflexões jurídicas e filosóficas sobre o conceito. 2017. $107 f$. Dissertação (Mestrado). Pontifícia Universidade Católica do Rio Grande do Sul, Programa de Pós-Graduação em Filosofia, Porto Alegre, 2017, p. 79.

31 SARLET, Ingo Wolfgang. Dignidade da pessoa humana na jurisprudência do Supremo Tribunal Federal. Revista Jurídica da Universidade do Sul de Santa Catarina, Santa Catarina, 2017, p. 30.

32 MIRANDA, Jorge. Manual de Direito Constitucional. 7. ed. Coimbra: Ed. Coimbra, 2013, p. 197.

33 ibid., p. 35-36.

34 ibid., p. 37-38. 
de personalidade (direito fundamental ao nome ${ }^{35}$ como também no que diz respeito ao direito de ressocialização do preso $^{36}$, e ainda, quanto a dignidade atrelada a união homoafetiva ${ }^{37}$, casos que serão debatidos mais adiante no presente trabalho.

As decisóes do STF sobre a dignidade da pessoa humana podem ser divididas em dois grupos: o primeiro, que aplica a dignidade como regra impeditiva de condutas tidas como inapropriadas, como o caso da vedaçáo da tortura e de qualquer tratamento desumano; e o segundo, que aplica a dignidade em uma dimensão positiva, ou seja, como dever do Estado de "assegurar prestaçôes indispensáveis ao mínimo existencial, de tal sorte que em favor do cidadão há que reconhecer um direito subjetivo, judicialmente exigível"38.

A utilizaçáo da dignidade da pessoa humana como critério interpretativo pode envolver tanto a identificação de um conteúdo em dignidade de outros direitos fundamentais quanto a interpretação "conforme a dignidade" de institutos jurídicos que implicam restrição a direitos ${ }^{39}$. Neste ponto, pode-se relacionar a discussão, em sede internacional, das degradantes condiçóes dos presídios integrantes do sistema carcerário brasileiro $^{40}$, e.g.. A dignidade, no caso comentado, parece ser violada em seu núcleo essencial.

\section{Dignidade humana em julgados do STF}

O STF, por meio de seus julgados, tem invocado o princípio da dignidade da pessoa humana em um grau crescente desde a promulgaçáo da CRFB, no ano de 1988. Seja de maneira principal ou ainda subsidiária. As decisóes apontam para a escolha, por parte do julgador, da alternativa que se demonstre mais adequada às exigências da dignidade da pessoa humana, ou, nos dizeres de Sarlet" ${ }^{41}$, "no sentido de in dubio pro dignitate".

Em pesquisa de jurisprudência realizada no site da Suprema Corte, na data de 7 de janeiro de 2020, foram localizados 407 acórdáos contendo a expressáo "dignidade humana”. Acrescente-se a isto a constante alegação por parte dos ministros de que o

35 RE no 248.869-1 (07-08-2003), relator Min. Maurício Corrêa.

36 NC 94163 (02-12-2008), relator Min. Ayres Britto.

37 ADI 4277 e APDF 132, relator Min. Ayres Britto.

38 SARLET, Ingo Wolfgang. Dignidade da pessoa humana na jurisprudência do Supremo Tribunal Federal. Revista Jurídica da Universidade do Sul de Santa Catarina, Santa Catarina, 2017, p. 43

39 ibid., p. 46.

40 Vide: MASSAÚ, Guilherme. O Estado brasileiro e suas violações aos direitos humanos em termos de justiça criminal: a inobservância do Art. 4o , II, da Constituição Federal. In: Arcénio Francisco Cuco e Bruno Rotta Almeida (Orgs.) Justiça Criminal e Direitos Humanos no sul global. Rio de Janeiro: Max Limonad, 2020.

41 ibid. p. 48. 
princípio da dignidade da pessoa humana seria postulado essencial ${ }^{42}$, valor-fonte ${ }^{43}$, e "o princípio mais importante da Constituição de 1988" "44.

Nas decisóes, evidencia-se casos em que a dignidade é mencionada apenas superficialmente, como no sentido de referir-se ao pedido da parte ou no relatório do julgado. Tais casos não são relevantes e não serão considerados para o fim do presente trabalho.

Em julgamento da Açáo Direta de Inconstitucionalidade no 4.277, o STF proferiu decisáo sobre o reconhecimento da uniáo estável entre pessoas do mesmo sexo como uma entidade familiar. O plenário da corte constitucional, em 2011, proferiu decisão em sentido positivo quanto a questáo abordada, tendo a dignidade da pessoa humana como um dos argumentos que serviu como base ao julgado.

$\mathrm{Na}$ mencionada decisão, o Min. Ayres Britto, relator das açóes, asseverou que a CRFB protege a livre escolha da sexualidade por parte de um indivíduo, salientando que "a proteção constitucional que faz da livre disposição da sexualidade do indivíduo um autonomizado instituto jurídico (...), dado elementar da criatura humana em sua intrínseca dignidade". O Min. Luiz Fux delineou argumentos a favor da autonomia da pessoa para decidir sobre sua orientação sexual:

Compete ao Estado assegurar (...) que cada um possa conduzir a sua vida autonomamente, segundo seus próprios desígnios e que a orientação sexual náo constitua óbice à persecuçáo dos objetivos pessoais. (...) essa ordem de ideias remete à questáo da autonomia privada dos indivíduos, concebida em uma perspectiva kantiana, como o centro da dignidade da pessoa humana.

A dignidade da pessoa humana é expressada na ementa do julgado, reconhecida como direito principal do qual emana o direito à preferência sexual. Consta que da dignidade se origina o direito a auto-estima "no mais elevado ponto da consciência do indivíduo", fazendo referência, ainda, ao direito à busca da felicidade. Isto quer dizer que, apoiado na dignidade, o ser humano deve ter o direito a buscar o sentimento de felicidade, e de tal busca faz parte a orientação e a afirmação de sua sexualidade.

Abrangendo a dignidade da pessoa humana, houve ainda a decisão da Suprema Corte na Ação de Descumprimento de Preceito Fundamental no 347, em setembro de 2015. Nela, o STF reconheceu existir o "estado de coisas inconstitucional" no sistema penitenciário do Brasil. Justamente devido ao fato de haver uma "violação passiva e persistente de direitos fundamentais, decorrente de falhas estruturais e falência de políticas públicas" ${ }^{\prime \prime}$ no país, o STF decidiu que a superlotação, proliferação de doenças, homicídios, espancamentos, tortura, violência sexual, entre outros pontos, fazem com

42 ARE 639.337 AgR, rel. min. Celso de Mello, j. 23-8-2011, 2a T, DJE de 15-9-2011

43 ADPF 347, rel. min. Marco Aurélio, j. 23-8-2015, plenário, DJE de 9-9-2015

$44 \mathrm{http} / /$ www.stf.jus.br/portal/cms/verNoticiaDetalhe.asp?idConteudo=386320 acesso em 07/01/2020.

45 ADPF 347 MC, Relator(a): Min. MARCO AURÉLIO, Tribunal Pleno, julgado em 09/09/2015, PROCESSO ELETRÔNICO DJe-031 DIVULG 18-02-2016 PUBLIC 19-02-2016 
que as prisóes brasileiras vivam uma inconstitucionalidade permanente que resulta em uma violação da dignidade humana.

Em seu voto, a Min. Carmen Lúcia asseverou que "qualquer que seja a condição daquele que existe, há de ser com dignidade”, e prosseguiu afirmando que:

[...] como o princípio da dignidade da pessoa humana está estampado no artigo 1o, fala-se pouco na existência digna. Entretanto, quando a gente faz visita à penitenciária, $o$ que há é uma ausência do existir digno e não uma experiência digna que nem os presos, nessa altura, de alguma forma, esperam.

Corroborando com a ideia de quehá, de fato, um "estado de coisas inconstitucional”, o Min. Celso de Mello aduziu em seu voto argumentos que ligam o direito básico de um preso a receber um tratamento não cruel, ou seja, minimamente justo e adequado e a dignidade da pessoa humana, conforme exposto a seguir:

[...] o Estado, agindo com absoluta indiferença em relação à gravidade da questão penitenciária, tem permitido, em razão de sua própria inércia, que se transgrida o direito básico do sentenciado de receber tratamento penitenciário justo e adequado, vale dizer, tratamento que não implique exposição do condenado a meios cruéis ou moralmente degradantes, fazendo-se respeitar, desse modo, um dos mais expressivos fundamentos que dáo suporte ao Estado democrático de direito: a dignidade da pessoa humana $(\mathrm{CF}$, art. 1o, III).

Percebe-se no voto do referido ministro apontamentos valiosos para a elucidação do conceito de dignidade humana para o STF. Qualificado como "valor-fonte", o princípio da dignidade da pessoa humana é lembrado como "fundamento da ordem republicana e democrática”, na medida em que serve como vetor interpretativo do sistema de direito constitucional positivo e instruído diversas decisões da Corte ${ }^{46}$.

Resta oportuno, ainda, lembrar um julgamento que se assemelha e se conecta com o ora analisado, qual seja o Recurso Extraordinário no 592.581/RS. Na decisão, mencionou-se a dignidade da pessoa humana como principal motivo fitando o respeito à integridade física e moral do preso ao serem promovidas medidas para execuçáo de obras emergenciais em penitenciárias, de maneira a não se aceitar a alegaçáo da reserva do possível por parte da Administração Pública.

Um pouco mais recente é a decisão do STF na Ação Direta de Inconstitucionalidade $n^{0} 4.275$, que permite ao transgênero que assim desejar, ainda que não tenha passado por cirurgia de transgenitalização ou realizado tratamento hormonal ou patologizante, a alteração de seu prenome e de seu gênero (sexo) de forma direta, no registro civil. A ação foi julgada em 01/03/2018.

Em seu voto, o Min. Celso de Mello dá destaque à dignidade da pessoa humana em um papel importante no panorama das relaçóes sociais contemporâneas, visto que, segundo ele, é "imperioso acolher novos valores e consagrar uma nova concepção de 
Direito fundada em nova visão de mundo" ${ }^{\text {‘7 }}$. Ainda segundo o ministro, a decisão dá primazia ao princípio objeto de estudo do presente trabalho, conforme se denota do seguinte trecho:

Esta decisão - que torna efetivo o princípio da igualdade, que assegura respeito à liberdade pessoal e à autonomia individual, que confere primazia $\mathrm{a} \backslash$ dignidade da pessoa humana e que, rompendo paradigmas históricos e culturais, remove obstáculos que inviabilizam a busca da felicidade por parte de transgêneros vítimas de inaceitável tratamento discriminatório - não é nem pode ser qualificada como decisão proferida contra alguém, da mesma forma que náo pode ser considerada um julgamento a favor de apenas alguns, mas, sim, de toda a coletividade social.

Não é custoso perceber que, no voto, o Min. Celso de Mello designa à dignidade da pessoa humana características que vão ao encontro do que a doutrina traz, como a liçáo de Ingo Sarlet ${ }^{48}$ de que o princípio da dignidade humana seria importante ao servir de ponto de partida para não apenas proteger, senão também criar direitos implícitos.

No mesmo sentido apontado aqui, o Min. Celso de Mello aduz em seu voto na Açáo Direta de Inconstitucionalidade 4.275 ${ }^{49}$ :

É por tal razáo que o magistério da doutrina - apoiando-se em valiosa hermenêutica construtiva e emancipadora e invocando princípios fundamentais (como os da dignidade da pessoa humana, da liberdade, da autodeterminação, da igualdade, do pluralismo, da intimidade, da náo discriminaçấo e da busca da felicidade) - tem revelado admirável percepçáo quanto ao significado de que se revestem tanto o reconhecimento do direito personalíssimo à identidade de gênero quanto a proclamaçáo da legitimidade éticojurídica do procedimento de adequaçáo dos assentamentos registrais ao nome social e à imagem dos transgêneros, independentemente de prévia cirurgia de transgenitalização, em ordem a permitir que se extraiam, em favor dessas mesmas pessoas, relevantes consequências no plano do Direito e, também, na esfera de suas relaçóes sociais, familiares e afetivas.

Interessante, ainda, reparar que o referido ministro menciona - no mesmo julgado - o postulado constitucional da busca da felicidade como decorrência do princípio da dignidade humana. Segundo o voto, o princípio tem papel relevante no processo de afirmação, gozo e expansão dos direitos fundamentais. A dignidade da pessoa humana está presente nos entendimentos expostos em Súmulas Vinculantes proferidas pelo STF, como no caso das que abordam o uso de algemas e a manutençáo do condenado em regime prisional mais gravoso, registradas, respectivamente, sob os números $11^{50}$ e $56^{51}$.

47 ADI 4.275, p. 123.

48 SARLET, Ingo Wolfgang. Dimensöes da dignidade: ensaios de filosofia do direito e direito constitucional. 2. ed. Porto Alegre: Livraria do Advogado, 2009, p. 35-36

49 ADI 4.275, p. 123-124.

50 Súmula Vinculante 11: "Só é lícito o uso de algemas em casos de resistência e de fundado receio de fuga ou de perigo à integridade física própria ou alheia, por parte do preso ou de terceiros, justificada a excepcionalidade por escrito, sob pena de responsabilidade disciplinar, civil e penal do agente ou da autoridade e de nulidade da prisão ou do ato processual a que se refere, sem prejuízo da responsabilidade civil do Estado."

51 Súmula Vinculante 56: "A falta de estabelecimento penal adequado não autoriza a manutenção do condenado em regime prisional mais gravoso, devendo-se observar, nessa hipótese, os parâmetros fixados no RE 641.320/RS." 
Na Súmula Vinculante 11, com base em julgados como os HC 91952, HC 89429 e HC 71195, o STF consignou que o uso das algemas só será permitido quando houver resistência, receio de fuga ou perigo à integridade física do preso ou de terceiros. Em sua fala no debate sobre a aprovação da referida Súmula Vinculante, o Min. Gilmar Mendes salientou que "[...] o abuso no uso de algemas jamais foi validado pela Corte. Esse tipo de exposição é uma forma de atentado também à dignidade da pessoa humana”. Ainda segundo o ministro, a exposição seria uma afronta à ideia de presunção da inocência, o que iria de encontro ao princípio da dignidade da pessoa humana (STF - DJe no 214/2008, p. 18).

Quanto a falta de estabelecimento penal adequado para o cumprimento da pena do condenado, a Súmula Vinculante 56, aprovada em 29/06/2016, aduz que não pode ocorrer a manutenção do apenado em regime prisional mais gravoso, sendo que os parâmetros expostos no julgamento do RE 641.320/RS devem ser observados.

No Recurso Extraordinário mencionado, novamente o Min. Celso de Mello enfrenta a questão cerne do recurso salientando a dignidade:

[...] o fato preocupante é que o Estado, agindo com absoluta indiferença em relaçáo à gravidade da questão penitenciária, tem permitido, em razão de sua própria inércia, que se transgrida o direito básico do sentenciado de receber tratamento penitenciário justo e adequado, vale dizer, tratamento que não implique exposição do condenado a meios cruéis ou moralmente degradantes, fazendo-se respeitar, desse modo, um dos mais expressivos fundamentos que dáo suporte ao Estado Democrático de Direito: a dignidade da pessoa humana (CF, art. 1o, III).

A dignidade da pessoa humana configurou-se, em decisão um pouco mais antiga, como justificativa para o STF ratificar e incentivar políticas públicas de inclusão de portadores de necessidades especiais à sociedade, conforme restou consignado na Ação Direta de Inconstitucionalidade 2.649, de relatoria da Min. Carmen Lúcia:

A Lei 8.899/1994 é parte das políticas públicas para inserir os portadores de necessidades especiais na sociedade e objetiva a igualdade de oportunidades e a humanização das relaçóes sociais, em cumprimento aos fundamentos da República de cidadania e dignidade da pessoa humana, o que se concretiza pela definiçâo de meios para que eles sejam alcançados.

Ao lado da cidadania, a dignidade da pessoa humana foi considerada, no julgado em questão, postulado importante na definição de meios para que a inclusão de pessoas vulneráveis se concretize, proporcionando humanização às relaçóes sociais.

\section{Projeção da dignidade humana no STF}

A normatividade do princípio da dignidade humana constitui-se em projeção da sua eficácia irradiante. Isto indica, nas decisões analisadas, que a dignidade humana não incidiu de forma isolada, mas como critério material interpretativo na incidência, 
também, de outros direitos. Com isto, tem-se que o Art. 1º, III, da CRFB delimita a materialidade de outros direitos. Contudo, salienta-se que nem sempre isto encontra-se explícito na decisão do Tribunal. Por isso, é essencial que a fundamentação das decisóes do Poder Judiciário aborde o como da incidência dos direitos no caso concreto.

Por conseguinte, diante dos casos citados é possível encontrar a relação da dignidade humana com outros princípios e outras regras. Ela, por si só, não contém densidade suficiente para ser delimitada, abstrata e isoladamente. Destarte, Na Ação de Descumprimento de Preceito Fundamental no 347, o que está em questão é a série de violaçóes de direitos fundamentais que ocorrem no ambiente carcerário brasileiro. Neste sentido, o princípio da dignidade humana encontra densificaçáo no descumprimento ou na não efetividade dos direitos fundamentais incidentes à pessoa humana encarcerada. Nota-se que sem a existência de violações aos direitos fundamentais, o fato de a pessoa estar presa não viola a sua dignidade, mas a questão se concentra em outras violaçóes de direitos como as más condiçóes das casas prisionais, a quantidade de pessoas por metro quadrado, as condiçóes de higiene dentre outros elementos violadores de direitos.

Destarte, na decisão da Ação Direta de Inconstitucionalidade no 4.277, o STF utilizou o princípio da dignidade humana para interpretar a igualdade (Art. 3º, IV, Art. 5o, caput, da CRFB) e a liberdade (Art. 5o, caput, da CRFB) no que diz respeito à opção sexual. Por conseguinte, a decisão foi por igualar em direitos a união dos casais homossexuais em relação à união heterossexual. Destaca-se que a dignidade humana não surge diretamente no caso concreto, pois os parâmetros jurídicos a serem empregados não recaem na diferença de tratamento, pois isto significaria que toda a diferença de tratamento jurídico seria indigna. Mas no caso em voga, a diferença se constitui indigna na medida em que não encontra sustentação nos princípios da igualdade e da liberdade. Para o STF não existe fundamentação jurídica sustentável para tratar de forma diferente situação idêntica, como é o caso das uniōes homossexuais em relação às heterossexuais. Assim, o mesmo fundamento (igualdade e liberdade) informa a decisão do STF na Ação Direta de Inconstitucionalidade 4.275, que permite ao transgênero adequar seus registros públicos $^{52}$.

\section{Consideraçóes finais}

No presente trabalho, demonstrou-se o princípio da dignidade da pessoa humana conforme o entendimento e as abordagens do STF, percebendo-se que, em consonância com as aproximaçóes conceituais da doutrina, a Suprema Corte coloca o princípio

52 Estas e outras conclusôes podem ser retiradas a partir da leitura de SANTOS, André Leonardo Copetti e LUCAS, Doglas Cesar. A (in)diferença no direito. Porto Alegre: Livraria do Advogado, 2015. Trata-se de livro fundamental para compreender como a diferença é tratada no direito. 
ora estudado como uma base, um valor-fonte, um postulado essencial para o Estado Democrático de Direito e para o desenvolvimento da sociedade.

Considerada um princípio constitucional, a dignidade da pessoa humana é retratada logo no primeiro artigo da CRFB como fundamento do Estado brasileiro, ao lado da soberania, cidadania, valores sociais do trabalho e da livre iniciativa e do pluralismo político. Tal fato dá ao referido princípio a característica de funcionar como uma bússola em busca da eticidade, ainda que sua dificuldade de conceituação - pela amplitude, abertura e imprecisão de seus contornos - seja fato praticamente uníssono entre os doutrinadores.

Enquanto valor a ser respeitado nas relaçóes sociais, a dignidade humana se apresenta como um princípio a ser aplicado em conjunto com outros princípios e regras. Pensar na dignidade humana como postulado independente, abstrato, isolado, não possibilita sua densificação com outros fatores como a efetividade dos direitos humanos, a igualdade e a liberdade. Para que se identifique a correlação nos julgados, é importante que o Poder Judiciário fundamente as decisóes apresentando a maneira através da qual incidiu a dignidade humana no caso concreto.

Ainda que não haja um consenso entre a jurisprudência e o conteúdo constitucional de países ao redor do mundo - o que notadamente já seria algo difícil de ocorrer —, eis que a maioria dos países expressamente consagram a dignidade humana em suas constituiçóes, percebe-se uma harmonia entre as acepçóes designadas. Em decisóes da $\mathrm{CIDH}$, o princípio é adotado de forma semelhante à maneira através da qual o STF enfrenta, na prática, casos nos quais a dignidade humana é abordada.

Sendo assim, em suas principais nuances e no cerne do conceito da dignidade da pessoa humana, a doutrina ao conceituar o princípio como princípio-base que norteia inúmeros outros direitos implícitos que dele surgem - como o direito à liberdade de manifestação de pensamento, a liberdade de orientação sexual e o direito a ter uma morte digna - dá a ele uma interpretação que vai ao encontro do que decide o STF em sua jurisprudência recente, eis que a Suprema Corte também tende a ditar a dignidade da pessoa humana como princípio basilar do qual se originam outros princípios considerados seus corolários.

\section{Referências}

BARROSO, Luís Roberto. A dignidade da pessoa humana no direito constitucional contemporâneo: a construção de um conceito jurídico à luz da jurisprudência mundial. Trad. Humberto Laport de Mello. Belo Horizonte: Fórum, 2014. 
BRASIL. Constituição da República Federativa do Brasil de 1988. Disponível em: http://www.planalto.gov.br/ccivil_03/constituicao/constituicao.htm. Acesso em: 23 de dezembro de 2019.

KANT, Immanuel. Fundamentação da Metafísica dos Costumes e Outros Escritos. São Paulo: Martin Claret, 2002.

LIBRELOTTO, Gicélia. Dignidade da Pessoa Humana: reflexóes jurídicas e filosóficas sobre o conceito. 2017. 107f. Dissertação (Mestrado). Pontifícia Universidade Católica do Rio Grande do Sul, Programa de Pós-Graduação em Filosofia, Porto Alegre, 2017.

MARTEL, Letícia de Campos Velho. Direitos fundamentais indisponiveis - os limites e os padröes do consentimento para a autolimitação do direito fundamental à vida. 2010. $475 \mathrm{f}$. Dissertação (Doutorado). Universidade do Estado do Rio de Janeiro, Centro de PósGraduação em Direito Público, Rio de Janeiro, 2010.

MASSAÚ, Guilherme. A dignidade humana em Pico dela Mirandola. Revista Direitos Culturais. v. 7, n. 13, 2012.

MASSAÚ, Guilherme. O Estado brasileiro e suas violaçóes aos direitos humanos em termos de justiça criminal: a inobservância do Art. 4º, II, da Constituiçáo Federal. In: Arcénio Francisco Cuco e Bruno Rotta Almeida (Orgs.) Justiça Criminal e Direitos Humanos no sul global. Rio de Janeiro: Max Limonad, 2020.

MIRANDA, Jorge. Manual de Direito Constitucional. 7. ed. Coimbra: Ed. Coimbra, 2013.

MORRIS, Clarence. Os grandes filósofos do Direito. São Paulo: Martins Fontes, 2002.

RAO, Neomi. On the use and abuse of dignity in constitutional law. Columbia Journal of European Law, Spring, v. 2, n. 2, 2008.

SANTOS, André Leonardo Copetti e LUCAS, Doglas Cesar. A (in)diferença no direito. Porto Alegre: Livraria do Advogado, 2015.

SARLET, Ingo Wolfgang. Dimensóes da dignidade: ensaios de filosofia do direito e direito constitucional. 2. ed. Porto Alegre: Livraria do Advogado, 2009;

SARLET, Ingo Wolfgang. Dignidade da pessoa humana na jurisprudência do Supremo Tribunal Federal. Revista Jurídica da Universidade do Sul de Santa Catarina, Santa Catarina, 2017.

SARLET, Ingo Wolfgang. A eficácia dos direitos fundamentais: uma teoria dos direitos fundamentais na perspectiva constitucional. 13. ed. Porto Alegre: Livraria do Advogado, 2018. 